\title{
Assessing the Level of Secondary Mathematics Teachers' Pedagogical Content Knowledge
}

\author{
Salma Saleh Moh'd ${ }^{1,2^{*}}$, Jean Uwamahoro ${ }^{1}$, Nzotungicimpaye Joachim ${ }^{3}$, John Aluko Orodho ${ }^{4}$ \\ ${ }^{1}$ University of Rwanda-College of Education (UR-CE), African Centre of Excellence for Innovative Teaching and Learning \\ Mathematics and Science (ACEITLMS), RWANDA \\ ${ }^{2}$ Abdulrahman Al-Sumait University, ZANZIBAR-TANZANIA \\ ${ }^{3}$ Unité de Recherche en Sciences Naturelles, ENS, BURUNDI \\ ${ }^{4}$ Kenyatta University, School of Education, KENYA
}

Received 1 March 2020 - Accepted 9 April 2021

\begin{abstract}
This study reports mixed-methods research findings, which assesses the level of mathematics teachers' pedagogical content knowledge (PCK) in selected secondary schools of Zanzibar. A Likert-scale questionnaire related to PCK self-assessment was administered to 69 teachers, 12 of whom were observed three times during lesson delivery in their respective mathematics classrooms. Both descriptive, inferential, and qualitative analyses were used. The study based on a questionnaire revealed that the level of mathematics teachers' PCK was moderate. However, significant differences in the levels of PCK based on teacher's education level and teaching experience were observed, while teachers' specializations showed no significant differences in their PCK level. The findings based on observation indicate that the level of PCK in classroom practices is low. This indicates the teachers' challenge in the implementation of PCK in classroom practices. There is, therefore, a need for more in-service training on raising teachers' PCK levels, which will eventually lead to improved mathematics teaching and learning.
\end{abstract}

Keywords: assessment, effective teaching, mathematics teachers, PCK level

\section{INTRODUCTION}

The study on the effectiveness of mathematics teaching and learning has attracted the attention of many researchers. Among their focus is on determining the quality of teachers as the core factor affecting mathematics teaching and learning, with much of their effort is on identifying the specific knowledge suitable for them to teach mathematics effectively (GessNewsome et al., 2017; Hurrell, 2013). Researchers indicated that good and quality mathematics teachers have sufficient knowledge and skills in teaching a particular topic (Baumert et al., 2010). Thus, they came to examine and assess this particular knowledge possessed by mathematics teachers for effective mathematics teaching and learning process.

Mathematical knowledge, skill, and attitude are vital equipment and the appropriate competencies for effective mathematics teaching and learning, particularly in the current world of science and technology (MoEVT, 2010). These competencies allow teachers to have a good plan, organize the lesson well, and use appropriate instructional strategies (Saad, Ghani, \& Rajendran, 2015). They also help teachers address their learners' difficulties, preconceptions, and misconceptions (Ma'rufi, Budayasa, \& Juniati, 2018). In this case, it is said that teachers are professionally and skillfully in integrating and transforming the knowledge and deliver it in a way that students can easily understand (Ma'rufi et al. 2018; Saad et al., 2015). This professional knowledge is known as pedagogical content knowledge (PCK). Shulman (1987), the inventor of this domain knowledge of teaching, defined PCK as "the blending of content and pedagogy into an understanding of how topics, problems, or issues are organized, represented, and adapted to the diverse interests and abilities of learners, and presented for

(c) 2021 by the authors; licensee Modestum. This article is an open access article distributed under the terms and conditions of the Creative Commons Attribution License (http://creativecommons.org/licenses/by/4.0/). 


\section{Contribution to the literature}

- This study brings additional contributions in the field of STEM education research.

- Particularly, it adds more information on the teachers' knowledge and suggests new methods for interested educational researchers.

- The study clearly informs on the role of the PCK towards improving mathematics teaching and address related challenges.

instruction" (p. 8). Hence, PCK is valuable in determining the unique construction of the lesson in classroom practice.

In the current sense of a mathematics teaching, there is a difference between a mathematician and a mathematics educator (Saad et al., 2015); that is the difference between being good in mathematics content and being good in teaching mathematics content. These two aspects of teachers' knowledge are not the same, though they are related because they complement each other. It is not enough for mathematics teachers to be just good in content by carrying out procedures for solving mathematics problems but unable to develop the appropriate strategies for illustration of mathematical concepts or ideas (Turnuklu \& Yesildere, 2007). Teachers with quality PCK can harmonize mathematics content knowledge with other knowledge of teaching mathematics to make comprehensive learning (Ma'rufi et al., 2018). Lack of synchronizing the knowledge will result in difficulties in teaching mathematics effectively. In this way, PCK can be considered the appropriate knowledge for bridging the gap between mathematicians and mathematics educators.

Mathematics teachers must have an appropriate level of PCK since this type of knowledge influences students' learning and hence leads to better performance. Through the proper level of PCK, the teachers are capable of implementing different theories of learning, including predicting pre-existing knowledge and misconception of the students, thinking of appropriate teaching strategies that can fit certain mathematics content, and also using multiple ways of presenting the concepts, to produce meaningful learning (Kathirveloo, Puteh, \& Matematik, 2014). According to Cueto et al. (2017), and Callingham, Carmichael, and Watson (2016), teachers with higher PCK are likely to have students with higher scores in mathematics. That is to say, mathematics teachers with a high level of PCK are more suitable for effectively transferring their mathematics knowledge and skills to the learners.

The newly reviewed curriculum for secondary schools in Tanzania (MoEVT, 2007) demands the mathematics teachers to have knowledge, skills, and attitude to build their competences in teaching mathematic, achieving the appropriate PCK level, and helping students to perform better. However, most of these teachers are having insufficient competences. Mohamed, Ramadhan, and Mbarouk (2017) revealed that among the reasons for poor learning outcomes in Zanzibar are teachers' inadequate competencies in knowledge, skill, and classroom effectiveness. Therefore, it is important to consider mathematics teachers at the secondary level as this is a level where the government expects to produce a workforce that can improve the country's socio-economic development (MoEVT, 2007).

Despite the several studies conducted about the significance of PCK for mathematics teachers (Berry et al., 2017; Danisman \& Tanisli, 2017; Even, Elen, \& Depaepe, 2015), very few studies were done on how to assess their PCK level. Moreover, the knowledge of PCK has received little attention in Unguja-island (Zanzibar) and Tanzania's perspective in general. We believe that understanding the level of mathematics teachers PCK may be the starting point in addressing their classroom competencies. Therefore, this study discusses assessing the level of mathematics teachers PCK in secondary schools of Unguja-Island (Zanzibar) of Tanzania.

\section{Theoretical and Empirical Perspective about PCK Assessment}

PCK in mathematics is assessed in different ways depending upon the goal of researchers and the context of their research. The use of different terminologies for assessing mathematics teachers PCK was revealed from various studies. Some of the researchers used measuring of mathematics teachers PCK (Rowan \& Atkins-Burnett, 2001), while others termed as examining of mathematics teachers PCK (Danisman \& Tanisli, 2017; Özdemir \& Soylu, 2017; Şahin, Gökkurt, \& Soylu, 2016) and others used explore mathematics teachers PCK (Kathirveloo et al. 2014). No matter which term was given to it, they all focus on determining the quality, level, status, and value of mathematics teachers PCK and mainly to provide information on where to improve when designing the teacher training programs.

The concept of PCK has been widely discussed by many scholars, where no common consensus has been reached the components to be included. However, these scholars came to agree to start with Shulman's concept of PCK, which contain two key components as the base (van Driel, Verloop, \& de Vos, 1998), and subsequently extended the concept to some other components of teacher's knowledge (Danisman \& Tanisli, 2017; Magidanga, 2017; Taşdan \& Çelik, 2016; Yıldırım \& Topalcengiz, 2019). The two critical elements presented 
by Shulman are knowledge representation of subject matter and understanding of students' learning difficulties, preconception, and misconception (Shulman, 1987).

The diverse concept of PCK provided an opportunity for different studies based on the researcher's interest in various components of PCK. As a consequence, some studies assessing mathematics teachers PCK on content and pedagogy (Lim \& Guerra, 2015), while others examining PCK based on knowledge of students only (Ma'rufi et al., 2018), and others mix knowledge of understanding students and knowledge of instructional strategies (Şahin et al., 2016). There are also studies that explored mathematics teachers' PCK in terms of content knowledge, curriculum knowledge, student knowledge, and teaching methods and strategies. This provides recognition that PCK is consistent with other domains' knowledge of teaching by which effective teachers consider them to be essential.

The literature shows that assessment of PCK has been done for both pre-service and in-service mathematics teachers and across different grade levels. Morrison and Luttenegger did the study (2015) focus on measuring PCK using teachers who teach at kindergarten. Lim and Guerra (2015) focused on assessing PCK for the preservice teachers at the primary level. Şahin et al. (2016) examined the PCK of prospective teachers of the secondary level while Danisman and Tanisli (2017), with Özdemir and Soylu (2017), examined the PCK of inservice mathematics teachers of secondary level. Generally, both types of teachers, whether pre-service or in-service of different grade levels, need to be assessed to obtain information that can help improve the standard and quality of mathematics teaching.

Different researchers have used several techniques in considering mathematics teachers' PCK. Some of the researchers used qualitative methods when assessing teachers' PCK (Turnuklu \& Yesildere, 2007; Ma'rufi et al., 2018). At the same time, others used quantitative approaches (Aksu, Metin, \& Konyalioglu, 2014; Lim \& Guerra, 2015). Some even used mixed methods to assess mathematics teachers PCK (Martinovic \& Manizade, 2017). In all of the above methods, researchers tried to provide the best understanding of their problem.

Researchers used various instruments of quantitative and qualitative methods to assess the teachers' quality of mathematics teachers based on PCK. Regarding the quantitative instruments, PCK scales were developed by some researchers, which can be accessed (Aksu et al., 2014; Yildirım \& Topalcengiz, 2019). Also, other researchers used qualitative research design in their study of examining mathematics teachers PCK. In their study, Özdemir and Soylu (2017) used eight open-ended questions as semi-structured interviews with forty-one mathematics teachers to obtain information about their PCK.
The assessment of mathematics teachers PCK can be determined through the subject and through a topic of subject; Because of this; some researchers choose to assess mathematics teachers PCK on specific topics such as fraction (Şahin et al., 2016), probability (Danisman \& Tanisli, 2017), function (Ma'rufi et al., 2018). However, some others (Lim \& Guerra, 2015) assess more than one topic. These researchers tried to find the area where teachers can effectively implement their PCK competence and develop different results and suggestions.

While many studies from the literature used the above mention strategies to evaluate mathematics teachers PCK, this study went further to assess the level of PCK for mathematics teachers, as this kind of assessment has not been given more attention to many studies about PCK for teachers. Therefore, this study used both self-assessment questionnaires and classroom observation to assess the level of secondary mathematics teachers PCK in Unguja-island of Tanzania effectively. The study was reported using the framework of teachers' mathematics content knowledge (MTCK), teachers' knowledge representation, and strategies (TKRS), together with teachers' knowledge of learners (TKL) as the components of PCK. As such this study aimed to answer the following questions:

1. What is the level of mathematics teachers PCK based on a self-assessment?

2. What are the main contributing factors in PCK difference observed among mathematics teachers?

3. How is the level of mathematics teachers' PCK in classroom practice?

\section{METHOD}

\section{Research Design}

The research employed a mixed-method explanatory sequential research design. Both quantitative and qualitative approaches were used in the collection of data. The mixed-method was found suitable to strengthen the quality of the study (Creswell, 2014).

\section{Participants}

Participants were 69 in-service teachers (34 male and 35 female) who teach mathematics in public secondary schools. These teachers were obtained randomly from three regions of the Unguja-Island of Zanzibar, Tanzania. These teachers were in the age range from 22 to 60, with teaching experience range 1-37 years. Although these teachers teach mathematics due to the scarcity of science and mathematics teachers in secondary schools, some did not specialize in mathematics in their teacher education development program. However, these teachers are in a continuous particular program, which converts them to teach 
Table 1. Distribution of the score in the classroom observation based on three components

\begin{tabular}{lcccc}
\hline Component of PCK & Number of items & Excellence (3 points) & Acceptable (2 points) & Deficiency (1point) \\
\hline MTCK & 8 & 24 & 16 & 8 \\
TKRS & 12 & 36 & 24 & 12 \\
TKL & 10 & 30 & 20 & 10 \\
Total & 30 & 90 & 60 & 30 \\
\hline
\end{tabular}

mathematics and science subjects. Out of these 69 teachers, 42 specialized in mathematics as their subject specialist while 27 specialized in other subjects. These participants were also in different education levels, of which four own certificates, 12 own diploma, 49 own bachelor's degrees, and 4 hold Master's degrees. All these 69 teachers were involved in filling up the questionnaire, 12 of whom participated in the classroom observation.

\section{Instruments and Validation}

The instruments used for data collection were questionnaires and classroom observation. The questionnaire consists of two sections. The first section presents demographic information about the teachers' age, gender, level of education, year of experience, and several times the teacher attended in-service training. The second section occupied the Likert-scales from 1 to 5 in the rank ranges from strongly disagree to strongly agree, respectively adapted from (Aksu et al. 2014), and it is in a self-assessment form. The items of this Likertscale were divided into three parts based on the components of PCK. These components were teachers' content knowledge, which occupied 15 items, teachers' knowledge of representation and strategies, which occupied 24 items, together with teachers' knowledge of learners, which occupied 11 items. The instrument was piloted, after which the reliability was checked using Cronbach Alpha Coefficient and found to be .876, which is above .85 (Pavot et al. 1991).

For the observation protocol, items were also observed in terms of the three components of PCK. There were 30 items in total, with eight items from content knowledge, 12 items from the knowledge of representation and strategies, and ten items from the knowledge of learners. The items were determined using three ranking ranges from deficiency to excellence in the rank scale range from 1 to 3 . The inter-rater reliability with the instrument was checked using Kappa and was found to be in substantial agreement with the size .643 (Landis \& Koch, 1997).

\section{Data Analysis}

The quantitative analyses of questionnaires were done using both descriptive and inferential statistics. The descriptive statistics used to analyze the PCK level for mathematics teachers in terms of three components, where mean and standard deviation were identified. Based on the earlier mentioned five Likert-scales, strongly disagree (1 point) to disagree ( 2 points) is set to be low level, neutral ( 3 points) is considered to be moderate level, and agree (4 points) to strongly agree (5 points) is regarded to be high level.

On the other hand, inferential statistics were used to check the statistical significance differences of mathematics teachers' level of PCK in educational levels, specializations, and teaching experiences. Hence, an independent $\mathrm{t}$-test compared the mean score of the groups (Pallant, 2005) within these three categories. The category used to compare the mean score of education level between teachers was grouped as certificate and diploma as one, while degrees and masters as another group. Regarding specialization, the mean score was compared between a group of mathematics specialization and other specialization. Moreover, the mean score for the teaching experience, was compared between the group of teachers having below up to five years as one group and above five years of experience as another group. The relative magnitude of the difference in the mean is determined using the eta square, which is interpreted using the eta square value suggested by (Cohen, 1988) with .01 as a small effect, .06 as a moderate effect .14 as large effect size. Statistical Package for Social Scientists (SPSS) version 20 was used to gather and analyzed these data.

The analysis of classroom observation was done by calculating the average score of each component of PCK observed in three teaching sessions for each of the 12 mathematics teachers in their teaching process. In this analysis, 3 points were given for the item that was excellence observed, 2 points were given for the item that was acceptable observed although not sufficiently, and 1 point was given to the item that was not observed. Hence, the threshold for each item's accepted score in each component of PCK is set to be $\mathbf{2}$ points.

Table 1 provides more clarification on the distribution of scores. The highest score of mathematics teachers' content knowledge (MTCK) is 24 points, and the lowest is 8 points, while the accepted score is starting from 16 points. For the teachers' knowledge of representation and strategies (TKRS), 36 points are considered the highest point, and 12 is the lowest point, while the accepted point is $\mathbf{2 4}$ scores. Furthermore, for the teachers' knowledge of learners (TKL), 30 points is considered to be the highest and 10 points is the lowest, while 20 score is the beginning of the accepted point. Teachers' overall average scores were also calculated for assessing their classroom practice in terms of PCK in general. The number of items indicates that the highest 
Table 2. Descriptive analysis of the self-assessment of mathematics Teachers' PCK based on three components

\begin{tabular}{llcc}
\hline & $N$ & Mean & Std. Deviation \\
\hline MTCK & 69 & 3.49 & .44 \\
TKRS & 69 & 3.50 & .62 \\
TKL & 69 & 3.47 & .66 \\
\hline
\end{tabular}

Table 3. Descriptive analysis of the self-assessment of mathematics teachers' PCK based on three categories

\begin{tabular}{lcccc}
\hline & & $\mathrm{N}$ & Mean & Std. Deviation \\
\hline Educational level & Certificate and Diploma & 16 & 3.25 & .36 \\
& Degree and Master & 53 & 3.56 & .48 \\
\hline Specialization & Math Specialization & 42 & 3.50 & .42 \\
& Other Specialization & 27 & 3.47 & .55 \\
\hline Year of experience & Below and up to 5 years & 34 & 3.33 & .35 \\
& Above 5 years & 35 & 3.64 & .53 \\
\hline
\end{tabular}

Table 4. Independent sample t-test for the case of educational level

\begin{tabular}{llcccc}
\hline $\mathrm{F}$ & Sig. & $\mathrm{t}$ & $\mathrm{df}$ & Sig. (2-tailed) & Effect size \\
\hline 2.052 & .157 & -2.393 & 67 & .02 & .0787
\end{tabular}

Table 5. An independent t-test for the case of specialization

\begin{tabular}{llllll}
\hline $\mathrm{F}$ & Sig. & $\mathrm{t}$ & $\mathrm{df}$ & Sig. (2-tailed) & Effect size \\
\hline 3.512 & .065 & .325 & 67 & .746 & .002 \\
\hline
\end{tabular}

Table 6. An independent t-test for the case of teaching experience

\begin{tabular}{llcccc}
\hline F & Sig. & $\mathrm{t}$ & $\mathrm{df}$ & Sig. (2-tailed) & Effect size \\
\hline 8.66 & .004 & -2.929 & 58.634 & .05 & .128 \\
\hline
\end{tabular}

score level of mathematics teachers PCK to be 90 points and the lowest score level to be that of 30 points in total. Therefore, the threshold for teachers' acceptable performance was set at 60 points. This type of analysis was adapted from the study (Turnuklu \& Yesildere, 2007) when determining PCK in mathematics for preservice primary mathematics teachers' perspectives in Turkey.

\section{FINDINGS}

\section{Quantitative Analysis of Mathematics Teachers' PCK}

\section{What is the level of mathematics teachers PCK based on a self-assessment?}

The descriptive analysis of the self-assessment questionnaire on the PCK level of mathematics teachers was done based on the three components; teachers' mathematics content knowledge (MTCK), teachers' knowledge of representation and strategies (TKRS) together with teachers' knowledge of learners (TKL). The result obtained from Table 2 shows that the mean score of each of the three components of PCK was observed to be moderate.

\section{What are the main contributing factors in PCK difference observed among mathematics teachers?}

The descriptive analysis of the self-assessment questionnaire on the PCK level of mathematics teachers was done based on the three categories of educational levels, specializations, and years of experience.

The result obtained from Table 3 revealed that there slight differences in the mean score of mathematics teachers' PCK for all three group categories of education levels, specializations, and experiences in teaching mathematics. However, further analysis was conducted to check if the differences observed within each category's groups are statistically significant.

An independent-samples t-test was conducted (see Table 4) to compare the mathematics teachers' PCK for the level of education. The table's result revealed a significant difference in mathematics teacher's PCK based on education level. However, the magnitude of the difference was observed to be moderate (eta squared $=$ 0.0787).

From Table 5, an independent-samples t-test was conducted to compare the mathematics teachers' PCK for specialization. The result from the table revealed that there is no significant difference in mathematics teacher's PCK for mathematics specialization. Consequently, the effect size was observed to be very small (eta squared $=0.002$ ).

An independent-samples t-test was conducted to compare the mathematics teachers' PCK in terms of teaching experience. The result from the table revealed that there is a significant difference in mathematics teacher's PCK based on experience and the magnitude of the difference was moderate (eta squared $=.128$ ). 


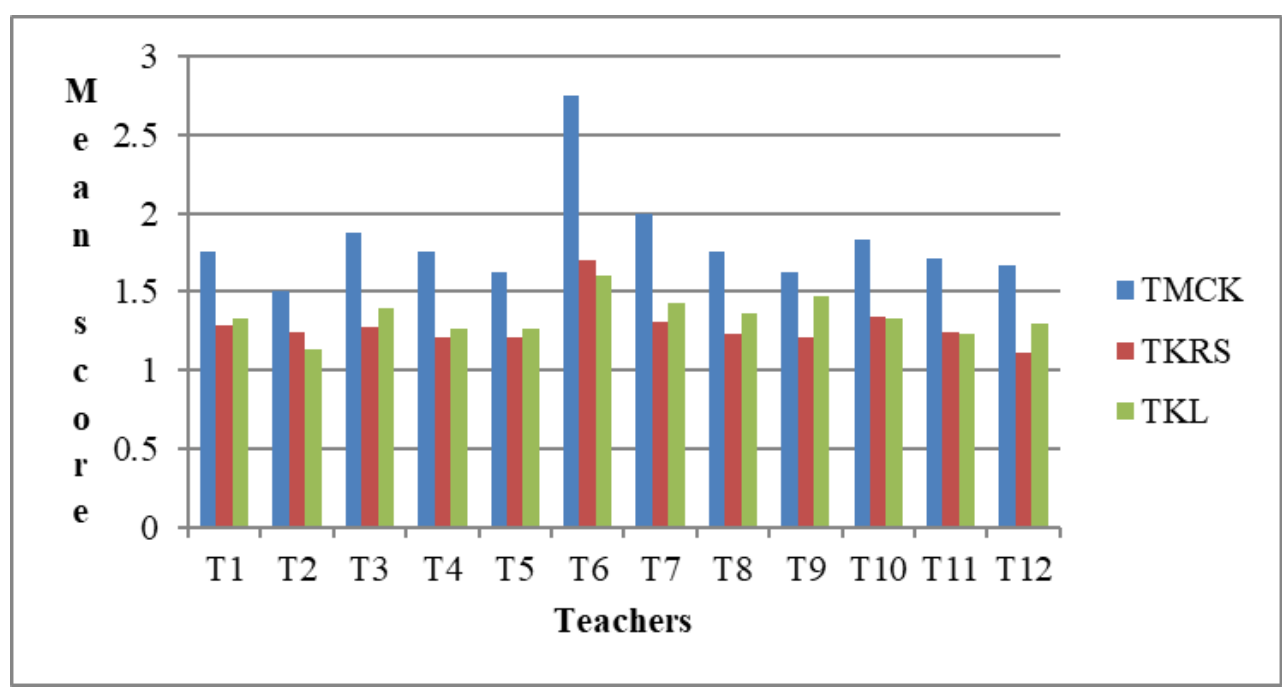

Figure 1. Mean score item of three-component of PCK for each of the twelve teacher

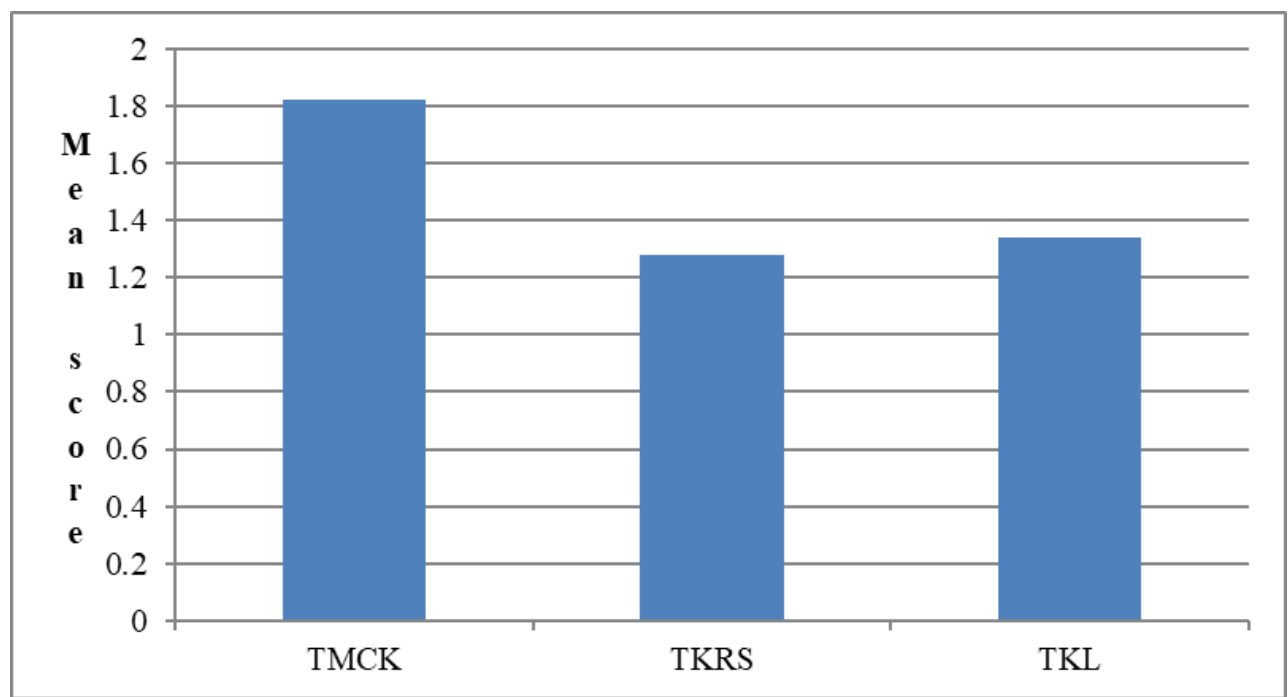

Figure 2. Mean score item of three components of PCK

Table 7. Overall average of mathematics teachers PCK in terms of three components

\begin{tabular}{lccc}
\hline MTCK & TKRS & TKL & PCK \\
\hline 14.56 & 16.19 & 9.619 & 40.37
\end{tabular}

\section{How is the level of mathematics teachers' PCK in classroom practices?}

The analysis of classroom observation was conducted to observe the PCK level of mathematics teachers during classroom practice. Figure 1 shows the result of the mean score of each of the three components for each of the twelve teachers. The result shows that only two out of twelve teachers were succeeded in reaching the accepted value for MTCK. However, for TKRS and TKL, none of the twelve teachers reaches the accepted value.

Figure 2 shows the overall mean score item of each of the three components of PCK. The overall teachers' content knowledge was observed to score higher compared to other components of PCK. However, all three components were not reached the accepted value of 2 points.
The result from Table 7 shows the overall average score of each of the three components. The average score of mathematics teachers' content knowledge (MTCK) was found to be 14.56. This value is less than the accepted level (which is set to be 16 points), which implies that mathematics teachers PCK in terms of content knowledge in the classroom practice is low. In terms of teachers' knowledge of representation and strategies (TKRS), 16.19 was found to be the average score in comparison with the accepted value of 24 points; hence the obtained overall score is low, and individually, no teacher was found to be above the accepted value. Also, all teachers' average score in terms of mathematics teachers' knowledge of learners (TKL) is found to be 9.6. This value is less than 20 points accepted score. Regarding an individual score, there was no record of any teacher who scored above the accepted level. 
Additionally, most of the teachers were even below half of the accepted level of score. This implies that mathematics teachers PCK in terms of knowledge of learners in the classroom practice is deficient.

The overall average score of all teachers in terms of all three components of PCK ((MTCK), (TKRS), and (TKL)) was found to be 40.37 . This value is less than the accepted score level which is 60 points. Therefore, PCK level for mathematics teachers in the classroom practice is low.

\section{Qualitative Analysis of Mathematics Teachers PCK}

The observation of mathematics teachers during classroom practice involved observing the items related to PCK in terms of three components of (MTCK), (TKRS), and (TKL). These teachers experienced these items during the delivery of the lesson in their respective mathematics topics. However, some difficulties related to some of these items were also observed;

\section{Mathematics teachers' content knowledge}

Lesson Introduction: The majority of these 12 teachers were observed to be less knowledgeable about how to introduce the lesson clearly. During their lesson introduction, these teachers did not observe to put more consideration on the learners' pre-existing knowledge; hence they did not use any activities to capture what learners have in their minds. Consequently, some of these teachers introduced the lesson themselves without incorporate students' thinking (T2, T4, T9, T11, and T12). In contrast, teachers brainstormed the learners base on the presented lesson with less interest in using learners' prior knowledge ( T1, T3, T5, and T10). Additionally, only three out of these 12 teachers started with activities and question related to life experience as a way of capturing learners' previous knowledge (example T6, $\mathrm{T} 7$, and $\mathrm{T} 8$ ).

Relate the lesson with the previous topics and with different aspects of mathematics concept: Five out of twelve teachers (T1, T6, T7, T8, and T10) observed to connect their lesson with the previous topics and all others remaining teachers did not observe to do so. In this sense, it provides an impression for students not to see the necessity of linking topics, so they end up treating each topic independently. On the other hand, only two teachers (T6 and T7) observed connecting the lesson with other aspects of mathematics. The remaining teachers stick to the same idea and failed to diverse the concept they taught to other different aspects of mathematics.

The use of appropriate materials in relation to mathematics topics being taught: Apart from chalk, board, all mathematics teachers except one (T6) did not use any other appropriate teaching materials in their teaching. This gives the researchers the impression that teachers might have thoughts that mathematics involves more of calculation, which does not necessarily require the use of more other materials; hence they were confident not to use any other appropriate materials to make students understand the topics better.

\section{Teachers' knowledge of representation and strategies}

Employs learner-centered approaches to engage learners in the learning process: Large numbers of these twelve teachers (T2, T3, T4, T5, T9, T10, T11, and T12) seemed to dominate the lesson and not to facilitate the lesson. Does this observation indicate less awareness of teachers about what learner center approach is? Hence, teacherstudent interactions were observed to play a significant role in the class compare to student-student interaction.

The use of different instructional strategies that fit the particular topic being taught: Almost all teachers (T2, T3, T4, T5, T9, T10, T11, and T12) observed to be fixed with the same single instructional strategy, regardless of any stage they taught in their lesson development. The most commonly used strategy for these teachers, in all three sessions they were observed, was only supported by the chalk and talk method of teaching with little involvement of students in the classroom activities. This indicated that teachers might not think of the varieties of strategies appropriate to teach a particular topic in mathematics, with less consideration of the learners' diversity in terms of their characteristics and level of understanding.

The use of teaching approaches that stimulate students' creativity and give them authorities to solve the problem: Due to the lack of implementation of the learner center approach in the classroom and the limited uses of instruction strategies to most of these teachers (T2, T3, T4, T5, T9, T10, T11, and T12), students' creativity was neither stimulated nor authorized in solve problems. Consequently, students became dull, passive, and partially presented in the classroom.

The use of multiple representations, varieties, appropriate, and real-life examples to clarify the concept. The use of multiple representations to explain the concept did not commonly observe to all teachers. Few of them tried to use not more than two ways of representing the same idea to students. Besides, some of these teachers were observed to provide many but not varieties of examples. All examples appear to stick to one way of presenting and clarifying the idea. Teachers were also not observed to consider real-life examples in their teaching.

\section{Teachers' knowledge of learners}

Adaptation to the characteristics and levels of the student with consideration of their individual differences: The observation shows that all teachers (T1, T2, T3, T4, T5, T6, T7, T8, T9, T10, T11, and T12) face difficulties in adapting to the characteristics and levels of each student. This could also be due to the single teaching strategy they used, which was considered to all students in general. Additionally, teachers did not observe to pay 
attention to learner's individual differences. Instead, they regarded learners in general even when they provided some tasks to students.

Diagnose Pupils' difficulties in understanding a concept and ability to challenge the learners cognitively: Considering the case of diagnosed students' difficulties, it became among the challenge for these mathematics teachers. Almost all teachers did not observe to identify individual difficulties in understanding the concept; instead, these teachers were succeeded in identifying the concepts which all students in general did not understand. The reason could be due to the teaching approach they chose, which regards the understanding of ideas for all students at a time. However, these teachers were also trying to ask students questions, though those questions were only challenged learners cognitively at the lower level.

Actively encouraged the students to ask questions and accept their ideas: Teachers did not encourage students to ask the questions; however, they usually used the common term "any question." Besides, students in the class developed the behavior of receiving everything from teachers. Hence, they became passive and not active. For this reason, they were not confident themselves even to provide ideas to their teachers so that the teachers could accept or reject them.

\section{DISCUSSION}

The overall result in the levels of mathematics teachers PCK was observed to be moderate in the teachers' self-assessment and low in the classroom practice. There could be some possible reasons for obtaining this kind of result;

All of the mathematics teachers involved in this study was given training in the teacher education development program in different levels of certificate, diploma, degrees, and masters. Additionally, various educational courses were provided during this academic development program which was also intended to improve teachers' knowledge in teaching mathematics. This is supported by Tajudin et al. (2015) that the professional development program is designed to improve teachers' way of teaching through the development of their knowledge, skills, and attitude. Thus, these teachers were believing and confidently themselves as knowing PCK as they provided a positive response on PCK in their self-assessment. And it is for this reason that the levels of PCK in their self-assessment became moderate.

Although teachers answered most of the questions to the level of moderate during this self-assessment, most of them show weaknesses, especially in the knowledge of representation and strategies together with knowledge of the learners. These two aspects of knowledge need special attention. As it was mention by Ma'rufi et al. (2018) "a teacher in transforming knowledge of content should use different representations, help students to make the connection between different representations to solve mathematic problems, identify students wrong thinking, be able to give respond toward students' questions" (p.2). Therefore, this moderate result emphasizes the need to influence teachers' PCK to a higher level.

Regarding the level of PCK based on different categories of educational levels, specializations, and teaching experiences, the result showed no significant difference in the level of mathematics teachers PCK observed in terms of specializations. This could be due to the fact that all teachers who are teaching at this level have sufficient content knowledge that is demanded in that level they taught. Moreover, teachers were also provided with a textbook that follows the syllabus as it was recommended by Ma'rufi et al. (2018) that various resources such as textbooks accompanied by the presentation of the concept in a simplifying way to the student should be used to transform content knowledge. That is to say; specializations have no effect on determining the level of PCK to mathematics teachers.

However, a significant difference was observed based on teachers' education level and teacher's experience in teaching. In a practical sense, the difference in the level of PCK for the teachers in terms of the level of education and experience was of moderate effect size. This implies that the level of education and experience might be the factor for the higher level of PCK for some secondary school teachers at Unguja-Island (Zanzibar) of Tanzania.

Teachers who receive educational skills at a higher level acquire more pedagogical skills than those at a lower level. This is supported by the report provided by Altinok (2013) on the impact of teacher knowledge on student achievement in 14 Sub-Saharan African Countries. The author revealed that knowledge in basic mathematics skills was observed in Tanzania (Zanzibar) for teachers with university education. Also, the duration of acquiring those educational skills is longer at a higher level than those who receive skills at a lower level. These enable students' teachers of higher-level to undergo more practical training and teaching practices under teacher educators' supervision.

Parallel to the result obtained by Ma'rufi et al. (2018) that among the essential factors of teachers PCK is teaching experience. It is expected that the more teaching experience, the higher the level of PCK. This is because the highly experienced teachers are expected to be aware of the problematic parts of the content, to be familiarized with theories, principal and mathematics concepts, expose to varieties of teaching resources, aware of different strategies and methodologies, able to identify effective methods and strategies for effective teaching, experience methods which are not effective, exposed to different students with different abilities, and also able 
to overcome different challenges with teaching and learning process. As it was suggested by Krauss et al. (2008) that PCK and CK might be a function of different levels of expertise.

The overall average of classroom observation showed that teachers' PCK level in the classroom is low. This indication gives the impression that although teachers' understanding of PCK is moderate, implementing this knowledge in classroom practices becomes challenging. PCK is observed to be the practical knowledge that informs the teachers' actual classroom action. Baumert et al. (2010) observed a positive relationship between teachers' PCK and instructional quality.

The teachers' poor implementation of PCK in the classroom could be due to different factors, including lack of implementation of theories of learning for teachers, of which some of these theories emphasized prioritizing students' prior knowledge during lesson introduction. Consequently, teachers could not be observed to build new knowledge based on students' pre-existing knowledge during the lesson's introduction.

The large class size which hinders some of the teachers from managing the class well. As a result, teachers face difficulties in considering individual differences, adaptation to students' characteristics and level, and even teaching resources become inadequate. Lack of creativity or incompetence in relating the lesson with previous topics or with different aspects of mathematics concepts was observed to be the challenge for almost all teachers. Most of the teachers treat the topics independently, which results in students facing difficulties in completing the task once if the problem connected with the previous topics or if the problems diverse to some aspect of the mathematics concept.

The indication that teachers were able to consider students' characteristics and students' differences would be observed using appropriate material, the use of different instructional strategies, the use of multiple representations of the concept, and the use of varieties, appropriate and real-life examples. Unfortunately, all of these were observed to be limited to the teachers when teaching in the classroom. As a result, teachers were able to capture only a few students in the classroom lesson, particularly those with a high understanding level. This might be caused by a lack of utilization of teaching resources for the mathematics teachers.

\section{CONCLUSION}

The level of mathematics PCK is among the factors that determine the effectiveness of mathematics teachers, which is an important part of the teaching and learning process. Teachers with higher levels in PCK are likely to be more effective in teaching secondary mathematics. This study revealed that the level of PCK for mathematics teachers in Zanzibar is moderate, while the implementation of PCK in classroom practices is low. That is to say, mathematics teachers at secondary schools in Zanzibar face a challenge in implementing PCK in the teaching and learning process. It is recommended to provide in-service training regarding the implementation of PCK in classroom practices and improve teaching strategies based on the learnercentered approach to enhance the teachers' level of PCK, which will enhance the performance of students in mathematics subjects. It is also recommended that the teacher's personal development increases PCK since the teacher's value is based on his capacity to impart knowledge and skills to the students.

Author contributions: All authors have sufficiently contributed to the study, and agreed with the results and conclusions.

Funding: This study has been fully funded by the African Centre of Excellence for Innovative Teaching and Learning Mathematics and Science (ACEITLMS).

Declaration of interest: No conflict of interest is declared by authors.

Acknowledgements: The authors would like to thanks the ACEITLMS for the great support and the teachers who agreed to participate in this study.

\section{REFERENCES}

Aimah, S., \& Purwanto, B. (2018). Indonesian teachers' perception on the implementation of lesson study: exploring teachers' awareness of pedagogical knowledge. Arab World English Journal (AWEJ), 9(4), 380-391.

https://doi.org/10.24093/awej/vol9no4.28

Aksu, Z., Metin, M., \& Konyalioglu, A. C. (2014). Development of the pedagogical content knowledge scale for pre-Service teachers: the validity and reliability study. Mediterranean Journal of Social Sciences, 5(20), 1365-1377. https:/ / doi.org/10.5901/mjss.2014.v5n20p1365

Altinok, N. (2013). The impact of teacher knowledge on student achievement in 14 Sub-Saharan African countries, Education for All Global Monitoring Report 2013/4. UNESCO.

Baumert, J., Kunter, M., Blum, W., Brunner, M., Voss, T., Jordan, A., Klusmann, U., Krauss, S., Neubrand, M., \& Tsai, Y.-M. (2010). Teachers' mathematical knowledge, cognitive activation in the classroom, and student progress. American Educational Research Journal, 47(1), 133-180. https://doi.org/10.3102/ 0002831209345157

Beers, B. (2006). Learning-Driven Schools: A Practical Guide for Teachers and Principals. ASCD.

Berry, A., Nilsson, P., Van Driel, J., \& Carlson, J. (2017). Analyzing science teachers' pedagogical content knowledge: a report on the second PCK summit. European Science Education Research Association ESERA. Ireland. 
Callingham, R., Carmichael, C., \& Watson, J. M. (2016). Explaining student achievement: the influence of teachers' pedagogical content knowledge in statistics. International Journal of Science and Mathematics Education, 14(7), 1339-1357. https: / / doi.org/10.1007/s10763-015-9653-2

Chambers, P. (2008). Teaching mathematics: developing as a reflective secondary teacher. Sage.

Cohen, J. (1988). Statistical power analysis for the behavioral sciences. Erlbaum.

Cueto, S., León, J., Sorto, M. A., \& Miranda, A. (2017). Teachers' pedagogical content knowledge and mathematics achievement of students in Peru. Educational Studies in Mathematics, 94(3), 329-345. https:/ / doi.org/10.1007/s10649-016-9735-2

Danisman, Ş., \& Tanisli, D. (2017). Examination of mathematics teachers' pedagogical content knowledge of probability. Malaysian Online Journal of Educational Sciences, 5(2), 16-34.

Das, S. k. (2017). A Study on teachers' mathematics pedagogical content knowledge and its effect on students' attitude towards mathematics and their scholastics achievement in mathematics of secondary level students of Kolkata. Advance Research Journal of Multi-Disciplinary Discoveries, 18(1), 143-146.

Dennis, N. N., Wambua, K. B., \& Peter, O. (2017). The effect of Smasse in-Service training on performance of mathematics in selected secondary schools in Kenya. European Scientific Journal, 13(10), 169-185. https:/ / doi.org/10.19044/esj.2017.v13n10p169

Even, M., Elen, J., \& Depaepe, F. (2015). Developing pedagogical content knowledge: Lessons learned from intervention studies. Education Research International, 2015, Article 790417. https:/ / doi.org/10.1155/2015/790417

Gess-Newsome, J., Taylor, J. A., Carlson, J., Gardner, A. L., Wilson, C. D., \& Stuhlsatz, M. A. (2017). Teacher pedagogical content knowledge, practice, and student achievement. International Journal of Science Education, 41(7), 944-963. https:/ / doi.org/10.1080/ 09500693.2016.1265158

Hatisaru, V., \& Erbas, A. K. (2017). Mathematical knowledge for teaching the function concept and student learning outcomes. International Journal of Science and Mathematics Education, 15(4), 703-722. https: / / doi.org/10.1007/s10763-015-9707-5

Hurrell, D. P. (2013). What teachers need to know to teach mathematics: an argument for a reconceptualised model. Australian Journal of Teacher Education, 38(11), 54-64. https://doi.org/ 10.14221 /ajte.2013v38n11.3

Ijeh, S. B., \& Nkopodi, N. N. (2013). Developing a theoretical model for investigating the mathematics and science teachers' PCK in South Africa and
Zimbabwe. Mediterranean Journal of Social Sciences MCSER Publishing, Rome-Italy, 4(14), 473-479. https://doi.org/10.5901/mjss.2013.v4n14p473

Kathirveloo, P., Puteh, M., \& Matematik, F. S. (2014). Effective teaching: pedagogical content knowledge. Proceeding of International Joint Seminar Garut. Indonesia.

Kisakali, J., \& Kuznetsov, D. (2015). Modeling factors influencing mathematics learning and performance in Tanzanian secondary schools. Asian Journal of Mathematics and Applications, 1-11.

Kitta, S. (2015). Development of mathematics teachers: Experience from Tanzania. International Journal of Education Science, 8(1-ii), 165-175. https:/ / doi.org/ 10.1080/09751122.2015.11917602

Krauss, S., Brunner, M., Kunter, M., Baumert, J., Blum, W., Neubrand, M., \& Jordan, A. (2008). Pedagogical content knowledge and content knowledge of secondary mathematics teachers. Journal of Educational Psychology, 100(3), 716-725. https:/ / doi.org/10.1037/0022-0663.100.3.716

Landis, J., \& Koch, G. (1977). The measurement of observer agreement for categorical data. Biometrics, 33(1), 159-174. https:/ / doi.org/10.2307/2529310

Lim, W., \& Guerra, P. (2015). Using a pedagogical content knowledge assessment to inform a middle grades mathematics teacher preparation program. Georgia Educational Researcher, 10(2), 1-15. https: / / doi.org/10.20429/ger.2013.100201

Luna, C. A., \& Aclan, E. G. (2015). The influence of teachers' mathematics pedagogy content knowledge training on pupils' mathematics achievement. American Journal of Educational Research, 3(10), 1311-1314.

Ma'rufi, Budayasa, I. K., \& Juniati, D. (2018). Pedagogical content knowledge: teacher's knowledge of students in learning mathematics on the limit of function subject. Journal of Physics: Conference Series, 954(1), 012002. https:// doi.org/10.1088/17426596/954/1/012002

Magidanga, F. S. (2017). Impediments towards enhancing the pedagogical content knowledge to secondary school teachers in Tanzania. International Journal of Education and Research, 5(1), 273-284. https:/ / doi.org/10.1155/2017/7282614

Maniraho, J. F. (2017). The pedagogical content knowledge (PCK) of Rwandan grade six mathematics teachers and its relationship to student learning. The University of KwaZulu-Natal. South Africa.

Marshal, J. H., \& Sorto, M. A. (2012). The effects of teacher mathematics knowledge and pedagogy on student achievement in rural Guatemala. International Review of Education, 58(2), 173-197. https:/ / doi.org/10.1007/s11159-012-9276-6 
Martinovic, D., \& Manizade, A. G. (2017). Using grounded theory to extend the existing PCK framework at the secondary level. Education Sciences, 7(60), 1-17. https://doi.org/10.3390/ educsci7020060

Mbugua, Z. K., Kibet, K., Muthaa, G. M., \& Nkoke, G. R. (2012). Factors contributing to students' poor performance in mathematics at Kenya certificate of secondary education in Kenya: a case of Baringo County, Kenya. American International Journal of Contemporary Research, 2(6), 87-91.

MoEVT. (2010). Basic mathematics syllabus for secondary schools, Form I-IV.

MoEVT. (2007). Curriculum for ordinary level secondary education in Tanzania. Tanzania Institute of Education.

MoEVT. (2016). Zanzibar Education Development Plan II2017/2018-2021/2022. Revolution Government of Zanzibar.

Mohamed, A., Ramadhan, H., \& Mbarouk, M. (2017). Zanzibar: Improving mathematics and science in schools. MS4SSA.

Morrison, A. D., \& Luttenegger, K. C. (2015). Measuring pedagogical content knowledge using multiple points of data. The Qualitative Report, 20(6), 804-816. https:/ / doi.org/10.46743/2160-3715/2015.2155

NCTM, N. C. (2000). Principles and standards for school mathematics. https://www.nctm.org/Standardsand-Positions/Principles-and-Standards /

Özdemir, G., \& Soylu, Y. (2017,). Examination of the pedagogical content knowledge of mathematics teachers. International Online Journal of Primary Education IOJPE, 6(1), 26-39.

Pallant, J. (2005). SPSS Survival Manual: A step-by-step guide to data analysis using SPSS for Windows (Version 12). Allen \& Unwin.

Pavot, W., Diener, E., Colvin, C. R., \& Sandvik, E. (1991). Further validation of the satisfaction with life scale: evidence for the cross method convergence of wellbeing measures. Journal of Personality Assessment, 57(1), 149-161. https:/ / doi.org/10.1207/s15327752 jpa5701_17

Robichaux, R. R., Rodrigue, P., \& Guarino, A. J. (2013). Ameliorating pedagogical competencies in mathematics for secondary school teachers. Creative Education, 4(3), 194-195. https://doi.org/10.4236/ ce.2013.43029

Rowan, B., \& Atkins-Burnett, S. (2001). Measuring teachers' pedagogical content knowledge in surveys: An exploratory study. Study of Instructional Improvement, 1-20.

Saad, N. S., Ghani, S. A., \& Rajendran, N. (2015). The sources of pedagogical content knowledge (PCK) used by mathematics teachers during instruction: A case study.

Şahin, Ö., Gökkurt, B., \& Soylu, Y. (2016). Examining prospective mathematics teachers pedagogical content knowledge on fractions in terms of students' mistakes. International Journal of Mathematical Education in Science and Technology, 47(4), 531-551. https://doi.org/10.1080/0020739X. 2015.1092178

Shulman, L. (1987). Knowledge and teaching: Foundations of the new reform. Harvard Educational Review, 57(1), 1-22. https://doi.org/10.17763/ haer.57.1.j463w79r56455411

Sulisworo, D., Nasir, R., \& Maryani, I. (2017). Identification of teachers' problems in Indonesia on facing the global community. International Journal of Research Studies in Education, 6(2), 81-90. https:/ / doi.org/10.5861/ijrse.2016.1519

Tajudin, N. M., Saad, N. S., \& Chinnappan, M. (2015). A path analysis of mathematics teachers' subject matter knowledge, pedagogical content knowledge, and professional learning. COSMED, (pp. 1-9).

Taşdan, B. T., \& Çelik, A. (2016). A conceptual framework for examining mathematics teachers' pedagogical content knowledge in the context of supporting mathematical thinking. European Journal of Education Studies, 2(5), 91-120.

Turnuklu, E. B., \& Yesildere, S. (2007). The pedagogical content knowledge in mathematics: pre-service primary mathematics teachers' perspectives in Turkey. IUMPST, 1, 1-13.

van Driel, J. H., Verloop, N., \& de Vos, W. (1998). Developing science teachers' pedagogical content knowledge. Journal of Research in Science Teaching, 35(6), 673-695. https://doi.org/10.1002/(SICI) 1098-2736(199808)35:6<673::AID-TEA5>3.0.CO;2-J

Williams, F. O., Yahaya, L., \& Owolabi, H. (2018). Teachers' knowledge indices as predictors of secondary school student's academic achievement in Kwara State, Nigeria. IAFOR Journal of Education, 6(1), 73-90. https:// doi.org/10.22492/ije.6.1.05

Yildırım, B., \& Topalcengiz, E. Ş. (2019). STEM pedagogical content knowledge scale (STEMPCK): a validity and reliability study. Journal of STEM Teacher Education, 53(2), Article 2. https:/ / doi.org/10.30707/JSTE53.2Yildirim

\section{http://www.ejmste.com}

